http://nv.nltu.edu.ua

https://doi.org/10.15421/40290311

$@ \bowtie$ Correspondence author

Article received 10.04.2019 p.

O. I. Kaspruk

Article accepted 25.04.2019 p.

ok@nepcon.org

удк 581.526.42:630.4

В. М. Скробала', М. В. Кабаль², О. І. Каспрук', А. П. Дида'

${ }^{1}$ Національний лісотехнічний університет Украӥни, м. Львів, Україна

${ }^{2}$ Карпатський біосферний заповідник, м. Рахів, Україна

\title{
ФІТОЦЕНОЛОГІЧНА ТИПОЛОГІЯ БУКОВИХ ЛІСІВ КАРПАТСЬКОГО БІОСФЕРНОГО ЗАПОВІДНИКА
}

Конструювання фітоценологічної типологічної схеми букових лісів Карпатського біосферного заповідника на основі домінантної класифікації здійснено способом графічної візуалізації результатів непрямої ординації щодо розподілу 33 видівдомінантів трав'яного покриву в розрізі 16 субформацій. Оцінку комплексних градієнтів середовища, які визначають структуру і напрямок варіювання лісової рослинності, виконано на основі аналізу відповідностей із видаленим трендом (DCA, Detrended Correspondence Analysis). Для інтерпретації осей ординації визначено кореляцію координат видів з їх екологічними параметрами за екологічними шкалами Г. Елленберга. Фітоценологічну типологічну схему букових лісів Карпатського біосферного заповідника можна представити у вигляді шестикутника, у центрі якого розташована субформація Fageta (sylvaticae), а в кутах: 1) Carpineto (betuli)-Fageta (sylvaticae), Fraxineto (excelsioris)-Fageta (sylvaticae); 2) Abieto (albae)-Piceeto (abietis)-Fageta (sylvaticae), Piceeto (abietis)-Abieto (albae)-Fageta (sylvaticae); 3) Piceeto (abietis)-Fageta (sylvaticae); 4) Sorbeto (aucupariae)-Fageta (sylvaticae); 5) Querceto (petraeae)-Fageta (sylvaticae); 6) Fraxineto (excelsioris)-Ulmeto (glabrae)-Fageta (sylvaticae), Querceto (roboris)-Fageta (sylvaticae). У тривимірному просторі типологічна схема має вигляд шестикутної піраміди, на вершині якої розташовані субформації Acereto (pseudoplatani)-Fraxineto (excelsioris)-Fageta (sylvaticae) i Ulmeto (glabrae)-Fageta (sylvaticae).

Ключові слова: домінантна класифікація; багатовимірна ординація; еколого-фітоценотичні ряди; лісова типологія.

Вступ. У ХХ ст. вітчизняні фітоценологи традиційно вивчали лісову рослинність на основі домінантної класифікації та еколого-лісівничої типології (Herushynskyi, 1996; Malinovskij, 1991). Ці класифікаційні схеми стали зручним інструментом аналізу різноманітності рослинного покриву у вигляді кадастрів типів лісу або продромусу рослинності. Інший аспект вивчення еколого-ценотичної диференціації рослинного покриву передбачає його впорядкування у певній системі координат відповідно до градієнта змін екологічних чинників (едафічна сітка Алєксєєва-Погребняка) або подібності рослинних угруповань за флористичним складом (еколого-фітоценотичні ряди В. М. Сукачова) (Didukh, 1992).

Великий обсяг фітоценологічних досліджень лісової рослинності Українських Карпат виконано на основі домінантної класифікації (Malinovskij, 1991). Зокрема це стосується і букових лісів Карпатського біосферного заповідника (КБ3) (Sukhariuk, 2006). Проте відсутність необхідних узагальнень не сприяла плідному використанню цих знань. Мета дослідження полягає у конструюванні фітоценологічної типології букових лісів на ос- нові домінантної класифікації.

Об'єкти і методи дослідження. Конструювання узагальненої типологічної схеми букових лісів КБЗ на основі домінантної класифікації здійснювали способом графічної візуалізації результатів непрямої ординації щодо розподілу 33 видів-домінантів трав'яного покриву в розрізі 16 субформацій. Оцінку комплексних градієнтів середовища, які визначають структуру і напрямок варіювання лісової рослинності, виконували на основі аналізу відповідностей із видаленим трендом (Detrended Correspondence Analysis) (Skrobala, 2010; Hammer et al., 2001). Для інтерпретації осей ординації визначали кореляцію координат видів 3 їх екологічними параметрами за екологічними шкалами Г. Елленберга (Ellenberg et al., 1992). Назви видів подано згідно з "Определителем высших растений Украины" (Prokudin, 1987).

Результати дослідження. Домінантну класифікацію рослинності можна представити у вигляді двовимірної матриці (Didukh, 1992), кожен стовпець якої відповідає субформації, а рядок - домінанту трав'яного покриву (асоціаціi). У найпростішому випадку кожний елемент

Інформація про авторів:

Скробала Віктор Михайлович, канд. с.-г. наук, доцент, кафедра ландшафтної архітектури, садово-паркового господарства та урбоекологіï. Email: skrobala@ukr.net; https://orcid.org/0000-0002-0606-8079

Кабаль Мирослав Васильович, завідувач лабораторії лісознавства. Email: myroslawk@gmail.com; https://orcid.org/0000-00029256-2531

Каспрук Олеся Ігорівна, канд. с.-г. наук, доцент, кафедра ландшафтної архітектури, садово-паркового господарства та урбоекології. Email: ok@nepcon.org

Дида Андрій Петрович, канд. с.-г. наук, доцент, кафедра ландшафтної архітектури, садово-паркового господарства та урбоекологіï. Email: adyda@ukr.net

Цитування за ДСту: Скробала В. М., Кабаль М. В., Каспрук О. І., Дида А. П. Фітоценологічна типологія букових лісів Карпатського біосферного заповідника. Науковий вісник НлТУ України. 2019, т. 29, № 3. С. 52-55.

Citation APA: Skrobala, V. M., Kabal, M. V., Kaspruk, O. I., \& Dyda, A. P. (2019). Fitocoenological typology of beech forests of Carpathian Biosphere Reserve. Scientific Bulletin of UNFU, 29(3), 52-55. https://doi.org/10.15421/40290311 
матриці може приймати значення 0 або 1, що характеризує відсутність чи наявність певної асоціації. Зазвичай еколого-фітоценотичну диференціацію рослинності на основі домінантної класифікації здійснюють способом ранжування домінантів трав'яного покриву та едифікаторів деревного намету, щоб ненульові елементи матриці розташувалися на діагоналі матриці (Didukh, 1992). Таке ранжування домінантів відображає закономірності впливу екологічних чинників. У цій роботі використовуємо дещо складніші обчислення, які дають змогу присвоїти видам трав'яного покриву і субформаціям числові значення, які можна порівняти 3 екологічними параметрами видів та середніми значеннями екологічних режимів місцезростань субформацій (Skrobala, 2010).

Букові ліси на території КБЗ представлені 16 субформаціями і 124 асоціаціями. Проте матриця на основі домінантної класифікації характеризується низькою інформативністю. Субформації Acereo (pseudoplatani)Fraxineto (excelsioris)-Fageta (sylvaticae), Fraxineto (excelsioris)-Ulmeto (glabrae)-Fageta (sylvaticae), Querceto (roboris)-Fageta (sylvaticae), Tlieto (platyphyllae)-Fageta (sylvaticae), Ulmeto (glabrae)-Fageta (sylvaticae) представлені тільки однією асоціацією, тоді як Fageta (sylvaticae) - 52 асоціаціями. Нерівномірність розподілу асоціацій по субформаціях різко знижує інформативність домінантної класифікації букових лісів КБЗ та можливості добування додаткової інформації. Так, 15 домінантів трав'яного покриву (Carex brizoides, Stellaria nemorum, Allium ursinum, Melica uniflora, Luzula sylvatica, Pteridium aquilinum, Dryopteris austriaca та інші) представлені тільки в одній субформації, переважно в Fageta
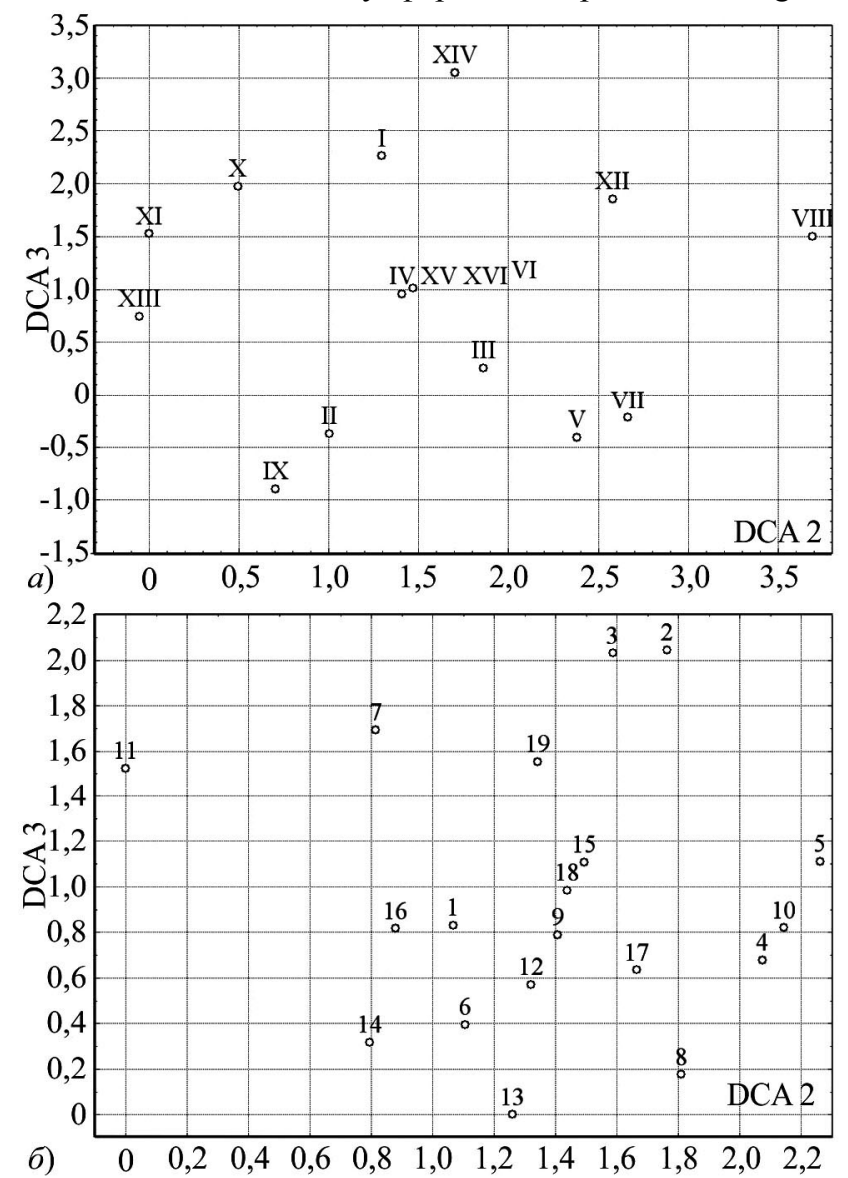

б) $\begin{array}{llllllllllll}0 & 0,2 & 0,4 & 0,6 & 0,8 & 1,0 & 1,2 & 1,4 & 1,6 & 1,8 & 2,0 & 2,2\end{array}$ Рис. 1. Типологічна схема букових лісів КБЗ: нумерацію субформацій римськими числами і домінантних видів арабськими числами наведено в тексті (sylvaticae). Ці види були виключені з аналізу, оскільки вони мали б однакові координати з відповідною їм субформацією. Більший внесок в інформативність матриці домінантної класифікації роблять види, які трапляються в декількох субформаціях. Так, Mercurialis perennis присутній в дев'яти субформаціях букових лісів, Galium odoratum - в семи, Dentaria glandulosa i Vaccinium myrtillus - у шести, Dryopteris filix-mas i Athyrium filixfemina в п'яти, Calamagrostis arundinacea, Carex pilosa, Festuca altissima, Lunaria rediviva, Oxalis acetosella, Petasites albus, Phyllitis scolopendrium - у чотирьох субформаціях. В ідеальному випадку для кожної асоціації потрібно виконати декілька геоботанічних описів, що дало б змогу включити в аналіз весь перелік видів пробних ділянок і збільшити інформативність даних завдяки переходу до системи координат вид - рослинне угруповання. Внаслідок ми відібрали 19 видів-домінантів трав'яного покриву, які характеризувалися найбільшою інформативністю: 1) Athyrium filix-femina; 2) Calamagrostis arundinacea; 3) Calamagrostis villosa; 4) Carex pilosa; 5) Dentaria glandulosa; 6) Dryopteris filix-mas; 7) Festuca altissima; 8) Galium odoratum; 9) Lunaria rediviva; 10) Luzula luzuloides; 11) Luzula sylvatica; 12) Mercurialis perennis; 13) Oxalis acetosella; 14) Petasites albus; 15) Phyllitis scolopendrium; 16) Rubus hirta; 17) Salvia glutinosa; 18) Sesleria heufleriana; 19) Vaccinium myrtillus. На їх основі виконано аналіз відповідностей із видаленим трендом, внаслідок якого для домінантів трав'яного покриву (нумерація арабськими числами) і субформацій визначено розташування на типологічних схемах (рис. 1-2).

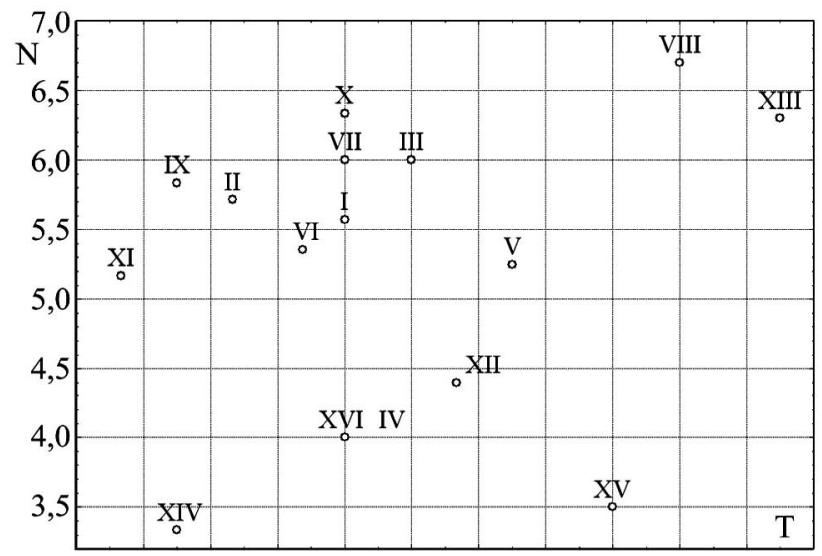

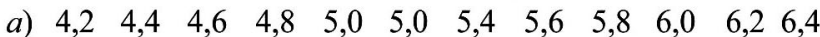

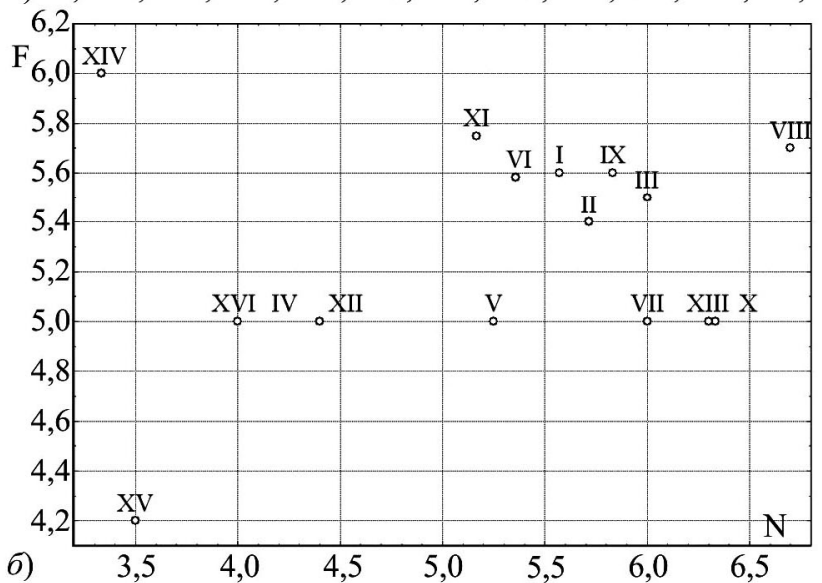

Рис. 2. Екологічний простір букових лісів КБЗ: Т - термічний режим, F - режим зволоженості, $\mathrm{N}$ - вміст азоту, бали за шкалами $\Gamma$. Елленберга; нумерацію субформацій римськими числами наведено в тексті 
Субформаціям букових лісів відповідає нумерація римськими числами: I. Abieto (albae)-Fageta (sylvaticae); II. Abieto (albae)-Piceeto (abietis)-Fageta (sylvaticae); III. Acereo (pseudoplatani)-Fageta (sylvaticae); IV. Acereo (pseudoplatani)-Fraxineto (excelsioris)-Fageta (sylvaticae); V. Carpineto (betuli)-Fageta (sylvaticae); VI. Fageta (sylvaticae); VII. Fraxineto (excelsioris)-Fageta (sylvaticae); VIII. Fraxineto (excelsioris)-Ulmeto (glabrae)-Fageta (sylvaticae); IX. Piceeto (abietis)-Abieto (albae)-Fageta (sylvaticae); X. Piceeto (abietis)-Acereto (pseudoplatani)-Fageta (sylvaticae); XI. Piceeto (abietis)-Fageta (sylvaticae); XII. Querceto (petraeae)-Fageta (sylvaticae); XIII. Querceto (roboris)-Fageta (sylvaticae); XIV. Sorbeto (aucupariae)-Fageta (sylvaticae); XV. Tilieto (platyphyllae)-Fageta (sylvaticae); XVI. Ulmeto (glabrae)-Fageta (sylvaticae).
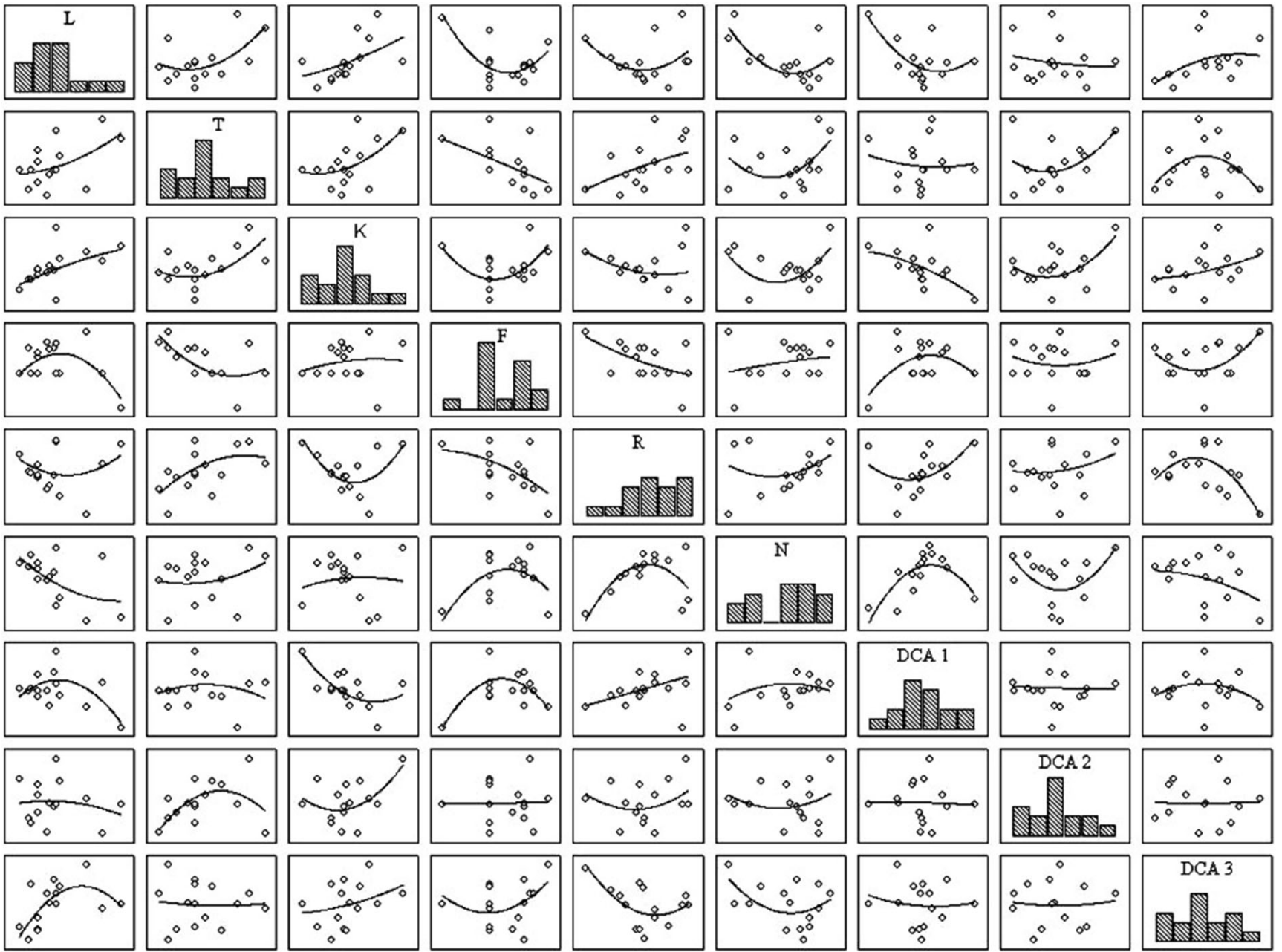

Рис. 3. Кореляція комплексних екологічних градієнтів з екологічними чинниками: $\mathrm{L}$ - освітленість, $\mathrm{T}$ - термічний режим, $\mathrm{K}$ - континентальність, $\mathrm{F}$ - режим зволоженості, $\mathrm{R}$ - кислотність, $\mathrm{N}$ - вміст азоту, бали за шкалами Г. Елленберга, DCA $\mathrm{A}_{\mathrm{i}}-$ осі типологічної схеми, комплексні екологічні градієнти середовища

Друга вісь типологічної схеми відображає закономірності висотної поясності букових лісів, зокрема збільшення параметрів термічного режиму із зменшенням висоти н.р.м. (див. рис. 1-3). Мінімальними значеннями функції DCA 2 характеризуються субформації Рісеeto (abietis)-Fageta (sylvaticae), Piceeto (abietis)-Acereto (pseudoplatani)-Fageta (sylvaticae), Piceeto (abietis)-Abieto (albae)-Fageta (sylvaticae), а максимальними - Fraxineto (excelsioris)-Fageta (sylvaticae), Querceto (petraeae)Fageta (sylvaticae), Carpineto (betuli)-Fageta (sylvaticae). Субформації Fraxineto (excelsioris)-Ulmeto (glabrae)-Fageta (sylvaticae), Querceto (roboris)-Fageta (sylvaticae) i Tilieto (platyphyllae)-Fageta (sylvaticae), які представлені тільки однією асоціацією. Ми не виключали їх з аналізу, проте у цьому випадку потрібно враховувати можливі відхилення цих субформацій від їх реального положення у фітоценологічному просторі. Так, низькі значення функції DCA 2 властиві субформації Querceto (roboris)-Fageta (sylvaticae), що не відповідає реальній картині вертикальної поясності в розподілі букових лісів.

Способом екстраполяції ми визначили наближене положення цих субформацій в екологічному просторі (див. рис. 2), де їм відповідають більші показники температурного режиму. До субформацій із низькими значеннями параметра температурного режиму можна додатково віднести також Sorbeto (aucupariae)-Fageta (sylvaticae). 
Для домінантних видів трав'яного покриву можна виділити екологічний ряд Luzula sylvatica, Festuca altissima, Petasites albus $\rightarrow$ Carex pilosa, Dentaria glandulo$s a$, Galium odoratum. Цей ряд частково порушується ацидофільними видами (Luzula luzuloides, Calamagrostis arundinacea). Слабка кореляція між параметрами термічного режиму та кислотності грунту свідчить про можливість поширення ацидофільних бучин на нижчих висотних рівнях. Низький вміст азоту та висока кислотність грунту можуть бути аналогом зменшення параметрів термічного режиму.

Третя вісь типологічної схеми відображає зростання освітленості у піднаметовому просторі, зменшення $\mathrm{pH}$ i вмісту азоту в грунті. Максимальними значеннями функції $\mathrm{DCA}_{3}$ характеризується субформація Sorbeto (aucupariae)-Fageta (sylvaticae), а мінімальними - Piceeto (abietis)-Abieto (albae)-Fageta (sylvaticae), Abieto (albae)-Piceeto (abietis)-Fageta (sylvaticae), Carpineto (betuli)-Fageta (sylvaticae). Для домінантних видів трав'яного покриву цей екологічний ряд має такий вигляд: Calamagrostis arundinacea, Calamagrostis villosa, Festuca altissima, Vaccinium myrtillus $\rightarrow$ Oxalis acetosella, Galium odoratum.

У лісовій типології для виділення типів лісорослинних умов використовують едафічну сітку. Ї̈̈ докладний варіант із використанням екологічних шкал (див. рис. 2) дає змогу уточнити положення субформацій, які представлені тільки однією асоціацією. Так, субформаціï Fraxineto (excelsioris)-Ulmeto (glabrae)-Fageta (sylvaticae), Querceto (roboris)-Fageta (sylvaticae) i Tilieto (platyphyllae)-Fageta (sylvaticae), які не мають спільних домінантів трав'яного покриву, характеризуються подібністю на основі екологічних параметрів, що не вдалося виявити у фітоценологічному просторі. На цьому прикладі можна переконатися, що еколого-лісівнича типологія у багатьох випадках має більшу інформативність. Для характеристики типу лісу використовують не тільки домінанти трав'яного покриву, а й чисельні види-індикатори, які в комплексі дають змогу точніше визначити положення рослинних угруповань та синтаксонів вищого рівня в екологічному та фітоценологічному просторі.
Висновки. Впорядкування фітоценологічної інформації на основі безтрендового аналізу відповідностей дає змогу виконати геометричну інтерпретацію фітоценологічної інформації і представити домінантну класифікацію у вигляді типологічної схеми. Фітоценологічну типологічну схему букових лісів Карпатського біосферного заповідника можна подати у вигляді шестикутника, у центрі якого розташована субформація Fageta (sylvaticae), а в кутах: 1) Carpineto (betuli)-Fageta (sylvaticae), Fraxineto (excelsioris)-Fageta (sylvaticae); 2) Abieto (albae)-Piceeto (abietis)-Fageta (sylvaticae), Piceeto (abietis)-Abieto (albae)-Fageta (sylvaticae); 3) Piceeto (abietis)-Fageta (sylvaticae); 4) Sorbeto (aucupariae)-Fageta (sylvaticae); 5) Querceto (petraeae)-Fageta (sylvaticae); 6) Fraxineto (excelsioris)-Ulmeto (glabrae)-Fageta (sylvaticae), (Querceto (roboris)-Fageta (sylvaticae)). У тривимірному просторі типологічна схема має вигляд шестикутної піраміди, на вершині якої розташовані субформації Acereo (pseudoplatani)-Fraxineto (excelsioris)-Fageta (sylvaticae) i Ulmeto (glabrae)-Fageta (sylvaticae).

\section{Перелік використаних джерел}

Didukh, Ja. P. (1992). Rastitelnyj pokrov Gornogo Kryma (struktura, dinamika, jevoljucija i ohrana). Kyiv: Scientific thought, 256 p. [In Russian].

Ellenberg, H., Weber, H. E., Dull, R., et al. (1992). Zeigerwerte von Pflanzen in Mitteleuropa. Scripta geobot., 18, 258. https://doi.org/10.1002/fedr.19931040323

Hammer, O., Harper, D. A. T., \& Ryan P. D. (2001). Past: Paleontological Statistics Software Package for Education and Data Analysis. Palaeontologia Electronica, 4(1), 1-9.

Herushynskyi, Z. Yu. (1996). Typolohiia lisiv Ukrainskykh Karpat. Lviv: Piramida, 208 p. [In Ukrainian].

Malinovskij, K. A. (Ed.). (1991). Prodromus rastitelnosti Ukrainy. Kyiv: Scientific thought, 272 p. [In Russian].

Prokudin, Yu. N. (Ed.). (1987). Opredelitel vysshih rastenij Ukrainy. Kyiv: Scientific thought, 548 p. [In Russian].

Skrobala, V. M. (2010). Bahatovymirna fitotsenolohichna typolohiia lisovoi roslynnosti Ukrainy. Scientific Bulletin of UNFU, 20(6), 1316. [In Ukrainian].

Sukhariuk, D. D. (2006). Bukovi lisy Karpatskoho biosfernoho zapovidnyka (poshyrennia, tsenotychna struktura ta monitorynh). Scientific Bulletin of Uzhhorod University. Ser. Biology, 19, 91-95. [In Ukrainian].

V. M. Skrobala', M. V. Kabal' , O. I. Kaspruk', A. P. Dyda'

${ }^{I}$ Ukrainian National Forestry University, Lviv, Ukraine

${ }^{2}$ Carpathian Biosphere Reserve, Rakhiv, Ukraine

\section{FITOCOENOLOGICAL TYPOLOGY OF BEECH FORESTS OF CARPATHIAN BIOSPHERE RESERVE}

Carpathian Biosphere Reserve is located in the Transcarpathian region on the south-western macro-slope of the Ukrainian Carpathians. Beech forests on the territory of Carpathian Biosphere Reserve are represented by 16 subformations and 124 associations. The construction of a generalized typological scheme of beech forests of Carpathian Biosphere Reserve on the basis of a dominance classification was carried out by means of graphical visualization of the results of indirect ordination in relation to the distribution of 33 species-dominants of herbal coverage in the context of 16 subformations. The evaluation of complex environmental gradients that determine the structure and direction of variation of forest vegetation was performed on the basis of Detrended Correspondence Analysis (DCA). To interpret the axes of ordination, the correlation of species coordinates with their environmental parameters on Ellenberg's ecological scales was determined. Organizing phytocoenological data on the basis of Detrended Correspondence Analysis allows executing a geometric interpretation of phytocoenological data and presents a dominance classification in the form of a typological scheme. The phytocoenological typological scheme of beech forests of Carpathian Biosphere Reserve can be represented as a hexagon, in the centre of which there is the subformation of Fageta (sylvaticae), and in the corners are as follows: 1) Carpineto (betuli)-Fageta (sylvaticae), Fraxineto (excelsioris)-Fageta (sylvaticae) 2) Abieto (albae)-Piceeto (abietis)-Fageta (sylvaticae), Piceeto (abietis)-Abieto (albae)-Fageta (sylvaticae) 3) Piceeto (abietis)-Fageta (sylvaticae) 4) Sorbeto (aucupariae)-Fageta (sylvaticae) 5) Querceto (petraeae)-Fageta (sylvaticae) 6) Fraxineto (excelsioris)-Ulmeto (glabrae)-Fageta (sylvaticae), Querceto (roboris)-Fageta (sylvaticae). In a three-dimensional space, the typological scheme has the form of a hexagonal pyramid, on the top of which there are the subformations Acereto (pseudoplatani)-Fraxineto (excelsioris)-Fageta (sylvaticae) and Ulmeto (glabrae)-Fageta (sylvaticae).

Keywords: dominance classification; multidimensional ordination; ecological phytocoenotic series; forest typology. 